REVISTA DE DERECHO UNED, NÚM. 23, 2018

\title{
¿ESTÁ EN CUESTIÓN EL MODELO SOCIAL EUROPEO?
}

\author{
IS THE EUROPEAN SOCIAL MODEL AN ISSUE?
}

Olga Calatrava Lesmes

Resumen: Las competencias sociales pertenecen al ámbito de los Estados miembros, sin embargo se puede hablar de un modelo social europeo que supone una unidad de valores sociales compartidos. El modelo social europeo promueve la ciudadanía social y combina el rendimiento económico, la justicia social y la solidaridad. La crisis económica ha erosionado los Estados del Bienestar de los países rescatados; se han vulnerado los derechos fundamentales de los ciudadanos; y se ha puesto en evidencia a Europa ante su falta de respuesta. Este artículo trata de analizar si es necesario renovar el modelo social europeo, si las normas de soft law y el método abierto de coordinación (MAC) son acertados y la conveniencia de un nuevo reparto de competencias entre la Unión y los Estados miembros. Asimismo, se hace referencia al nuevo Pilar Europeo de Derechos Sociales, anunciado por Juncker en 2015 que se presenta como una oportunidad para abordar la nueva dimensión social europea. Es fundamental que se garanticen los derechos fundamentales y sociales por los órganos jurisdiccionales en tiempos de crisis económica, de modo que se equilibre lo económico y lo social. Finalmente, se debe promover la adhesión de la Unión Europea a la Carta Social Europea revisada en el marco del nuevo Pilar Europeo de Derechos Sociales.

Palabras clave: Unión Europea, Modelo Social Europeo, Método Abierto de Coordinación y derechos sociales. 
Abstract: The social competences fall within the scope of the Member States, nevertheless we may consider that a European social model implies shared social values. The European social model promotes social citizenship and combines economic performance, social justice and solidarity. The economic crisis eroded the welfare state of rescued countries, infringing citizens fundamental rights and showing Europe's lack of response. The present work aims to analyze the need to reform the European social model, if the soft law rules and the Open Method of Coordination (OMC) are effective and if a new distribution of competences between the European Union and Member States is necessary. Furthermore, particular reference is made to the new European Pillar of Social Rights, announced by Jean-Claude Juncker in 2015, which seems to be an opportunity to address the new European social dimension. In times of economic crisis, it is essential that the jurisdictional organs guarantee the fundamental and social rights so that a balance between the economic and the social areas is found. Finally, the accession of the European Union to the revised European Social Charter should be promoted within the framework of the new European Pillar of Social Rights.

Keywords: European Union, European social model, Open Method of Coordination and social rights.

Recepción original: 09/05/2018

Aceptación original: 09/07/2018

Sumario: I. El modelo social europeo.-I.1. Concepto, definición y la necesidad de su actualización. I.2. El Método abierto de coordinación, ¿una metodología eficaz? a) Definición y regulación; b) Funcionamiento del MAC; c) Dualismo institucional. I.3. El Pilar Europeo de Derechos Sociales. Una apuesta por la nueva dimensión social.-II. La Carta Social Europea. Debate sobre su adhesión.III. El TJUE como garante constitucional de los derechos fundamentales.-IV. Conclusiones.-V. Bibliografía utilizada.

\section{EL MODELO SOCIAL EUROPEO}

\section{I.1. Concepto, definición y la necesidad de su actualización}

La Unión Europea ha venido incorporando progresivamente un conjunto de normas, disposiciones y actuaciones que establecen y 
desarrollan principios, procedimientos y derechos de protección social $^{1}$ a favor de los ciudadanos europeos.

Esta actuación jurídico-normativa habría conformado, según algunas aproximaciones, lo que se ha venido denominando como «modelo social europeo» común a los Estados miembros ${ }^{2}$. La plasmación normativa de este modelo (derecho social comunitario), en coordinación con las constituciones de los Estados sociales nacionales, habría conformado un "constitucionalismo social multinivel europeo» que actuaría como instrumental jurídico garantista de los derechos sociales de los ciudadanos.

González Vázquez ${ }^{3}$ considera que el término «Modelo Social Europeo" se sigue utilizando para describir los elementos comunes a los regímenes sociales vigentes en la Unión. Existen una serie de valores comunes a los Estados miembros como son: la reducción de la pobreza y la exclusión social, la mejora de la equidad en la distribución de la renta, la promoción de la igualdad de oportunidades o la prestación de los seguros sociales. Pero los sistemas nacionales se ven reforzados a nivel supranacional gracias a la intervención de la Unión Europea. Por ello, el concepto «Modelo Social Europeo» no puede ser considerado fuera del contexto marcado por la influencia de las instituciones europeas en las políticas sociales de los Estados miembros.

Sin embargo, tal y como se desarrollará a continuación, la Unión Europea no pretendía la construcción de un modelo social común y se consideraba que la integración del mercado no debía ser causa de inquietud, todo lo contrario se confiaba plenamente en su capacidad para producir el progreso social.

El Tratado de Roma plasmó la teoría que guió el primer periodo de las normas de la Comunidad Económica Europea con incidencia social, hoy también recogida en el apartado 3 del artículo 151 del TFUE, que afirmaba la relación directa entre la consecución del mercado común y la mejora de las condiciones de vida del trabajo.

${ }^{1}$ Guamán, A. y Noguera, A. Derechos sociales, integración económica y medidas de austeridad: la UE contra el constitucionalismo social. Editorial Bormazo; año 2014; págs. 17-30.

2 Sobre el concepto de «modelo social europeo», vid. Barón Crespo, E., «Constitución y modelo social europeo», en Estudios de Economía Aplicada, vol. 27-3, año 2009, págs. 599-608.

${ }^{3}$ González Vázquez, I., «El Cambio de Orientación de la Política Social Comunitaria del Estado del Bienestar a la Sociedad del Bienestar». Universidad de Sevilla, año 2011. VI Premio Andaluz de Investigación sobre Integración Europea 2012, págs. 167-171. 
Asimismo, el artículo 118 a) reguló la armonización de las legislaciones nacionales en materia laboral y social. En particular disponía que «los Estados miembros procurarán promover la mejora, en particular del medio de trabajo, para proteger la seguridad y la salud de los trabajadores, y se fijarán como objetivos la armonización dentro del progreso, de las condiciones existentes en este ámbito» ${ }^{4}$.

Con el Tratado de Roma se optó porque las competencias sociales perteneciesen al ámbito estatal. Se efectuó así el llamado decoupling, elevando el ámbito supranacional únicamente para la efectiva realización de las libertades de circulación, en la que se incluía a los trabajadores, y el mantenimiento de la competencia en el mercado interior, mientras que las competencias sociales permanecían en el ámbito estatal.

El mencionado reparto competencial entre la actividad estatal y la comunitaria en los campos de la economía y la política social fue desde el inicio precario y la armonización antes referida tampoco dio los resultados esperados. A pesar de todo ello, los países europeos han sabido construir un modelo social que combina rendimiento económico, justicia social y solidaridad, y en el que existen derechos sociales, una regulación laboral avanzada, sistemas eficientes de protección social, con un papel relevante de las organizaciones de trabajadores y de la negociación colectiva. Aunque los sistemas sociales nacionales sean muy diferentes, se ha podido hablar de un "modelo social europeo» que dentro de una diversidad de sistemas nacionales supone una unidad de valores sociales compartidos y que ha permitido convertir la Unión Europea en un espacio de prosperidad.

El Modelo Social Europeo, en definitiva, promueve la ciudadanía social ${ }^{5}$ entendida como una limitación a la desigualdad social y económica, una mayor protección a los más vulnerables y un partenariado social activo. Como objetivo estratégico, el Modelo Social Europeo auspicia el crecimiento económico sostenido y sostenible basado en la cohesión social.

Ciertamente y observado desde abajo, la realidad del bienestar social europeo aparece como un caleidoscopio diverso de sedimentos y peculiaridades y una mezcla de diversidad y sinergias, pero sin

${ }^{4}$ Sobre el artículo 118.a) del Tratado de Roma, ver: Martínez Rocamora, L., «La Política social de la Comunidad económica Europea», Cuadernos de la Facultad de Derecho, Universidad Islas Baleares, 1991, Vol. 17, páginas 65-70.

5 Moreno, L., y Serrano, A., "Europeización del Bienestar y activación». Revista Política y Sociedad, 2007, Vol. 44; núm. 2; págs. 33-34. 
embargo la cobertura de las necesidades básicas y la promoción de la ciudadanía son objetivos compartidos.

A pesar de la diversidad de sus formas y manifestaciones, cabe identificar al modelo social europeo ${ }^{6}$ como aquel basado en la solidaridad colectiva y que es el resultado del conflicto y la cooperación social en los tiempos contemporáneos. La solidaridad social ha sido frecuentemente considerada como un fundamento del Estado del Bienestar. Existe una creencia generalizada de que el modelo social europeo es algo que proporciona identidad y unidad social en la mayoría de los estados miembros de la Unión Europea, en contraste con otros sistemas de protección donde la individualización es uno de los rasgos característicos de las políticas del bienestar (USA). La construcción de «suelos» o «redes» $\mathrm{y}$ «recursos» para atender las necesidades más elementales de los ciudadanos es una preocupación básica y compartida por los países europeos. La lucha contra la pobreza y la exclusión social juega un papel fundamental en el modelo social europeo, así como la promoción de la ciudadanía social.

Sin embargo, no es menos cierto que la internacionalización creciente de los intercambios y la integración de los mercados por la apertura de las economías han reducido la capacidad de acción y la autonomía de los Estados en materia social ${ }^{7}$, cuya problemática sin embargo, tiene una dimensión comunitaria que es la única que ahora puede garantizar la viabilidad de los sistemas sociales nacionales. Además, hemos visto como la crisis económica ha erosionado, singularmente, los Estados del bienestar de los países que han firmado los memorándums de entendimiento y que en definitiva han sido rescatados. Se hace necesario que desde Europa se impulse una mayor protección social y una mayor garantía de los derechos sociales. No se trata así de cambiar el modelo social europeo sino de renovarlo sin modificar sus principios, pero si sus métodos e instrumentos para responder eficazmente y con realismo a las nuevas necesidades sociales.

El modelo social europeo debe conformarse en el ámbito de la Unión a través de una mayor coordinación de las políticas sociales. Se hace necesario valorar un nuevo reparto de competencias entre la Unión y los Estados que eviten los efectos destructivos del juego

${ }^{6}$ Moreno, L., "Reformas y Reestructuración del Estado del Bienestar en la Unión Europea». Instituto de Políticas y Bienes Públicos (IPP) CSIC, Working Paper 2004-09, págs. 3-4.

7 Navarro Nieto, F., Rodríguez Piñero Royo, Miguel C., y Gómez Muñoz, J.M., Manual de Derecho Social de la Unión Europea. Tecnos, 2011, págs. 23-35.

(c) UNED. Revista de Derecho UNED, núm. 23, 2018 
competitivo, y a la vez, promover el acercamiento y compatibilidad de los diversos sistemas nacionales.

\section{I.2. El método abierto de coordinación, ¿una metodología eficaz?}

a) Definición y regulación

El método abierto de coordinación (MAC) es una creación original diseñada en el marco del proceso de construcción europea con el objeto de articular la acción de la Unión Europea (UE) y de los Estados miembros en determinados ámbitos materiales respecto de los cuales, por uno $\mathrm{u}$ otros motivos se ha excluido la aplicación de las técnicas de integración y de la típica cooperación ${ }^{8}$. En otras palabras, se trata de una forma intergubernamental de hacer política que no deriva en medidas legislativas de la UE de carácter vinculante ni exige que los países de la UE introduzcan nuevas leyes o modifiquen su legislación.

La regulación del MAC supone el recurso a una combinación de derecho originario y de normas de soft law en función de cada materia. El recurso al soft law o "norma suave» ${ }^{9}$ no es nuevo en el Derecho comunitario. El derecho blando o las normas suaves tienen como finalidad hacer frente a la inadaptación o la inexistencia de normas ${ }^{10}$. Teniendo en cuenta que no existe una definición exacta del término, se habla a menudo de autorregulación, de reglamentación voluntaria, de co-reglamentación o de casi-reglamentación. El MAC forma parte de esta nueva generación de dispositivos no obligatorios de buen gobierno denominados soft law governance, que están influyendo en el fenómeno de la europeización como proceso, en comparación con los útiles tradicionales de gobierno.

Estos modos alternativos de regulación normalmente aparecen en dominios donde es particularmente difícil convencer a los Estados Miembros a que renuncien a su competencia a favor de una

${ }^{8}$ Cafaro, S., «La méthode ouverte de coordinaction, l'action communautaire et le rôle politique du Conseil européen» en Mélangesen hommage a Jean-Victor Louis, Ed. ULB, 2003, Vol. II, págs. 204 y ss.

9 Pérez Menayo, V., «El método abierto de coordinación en la UE. ¿Una fórmula institucional de evaluación? en Gestión y Análisis de Políticas Públicas, mayo-diciembre 2004, pág. 74 .

10 Imani, E., "Méthode ouverte de coordinatión». E-juristes. Febrero de 2005. http://www.e-juristes.org/methode-ouverte-de-coordination647/ (Consulta 30 de abril de 2005). 
competencia comunitaria, mientras que a su vez la convergencia de las políticas nacionales se revela indispensable para avanzar en la integración europea.

Con todo ello, la Unión Europea pasa de estar exclusivamente gobernada por el método comunitario tradicional ${ }^{11}$, a estarlo también por nuevos modelos de gobernanza. Es decir las policy-making europeas han evolucionado hacia la nueva gobernanza, en donde se sitúa el MAC.

La Estrategia de Lisboa adoptada en el Consejo Europeo de los días 23 y 24 de marzo de 2000, con el objetivo estratégico de convertir a la UE en la economía basada en el conocimiento más competitiva y dinámica del mundo, supuso la introducción del MAC, su caracterización más precisa como modalidad de acción europea y su definición como uno de los protagonistas principales de esta agenda europea.

No fue hasta el Tratado de Lisboa (año 2007), cuando se introdujo la consagración normativa del método abierto de coordinación ${ }^{12}$. El método abierto de coordinación (MAC) se creó en el marco de la política de empleo y el proceso de Luxemburgo, y se definió como un instrumento de la Estrategia de Lisboa. El MAC establece un marco de cooperación entre los Estados miembros, con el objeto de lograr la convergencia entre las políticas nacionales para realizar algunos objetivos comunes. En el ámbito de este método intergubernamental, los Estados miembros evalúan a otros Estados miembros y la Comisión desempeña únicamente una función de supervisión.

El artículo 5.2 TFUE establece que «la Unión tomará medidas para garantizar la coordinación de las políticas de empleo de los Estados miembros, en particular definiendo las orientaciones de dichas políticas». Junto a esta imposición a la Unión, el artículo 5.3 TFUE la habilita para poder tomar iniciativas para garantizar la coordinación de las políticas sociales de los Estados miembros, como ya se está intentando especialmente en materia de pensiones.

11 Pérez Menayo, V., «El método abierto de coordinación en la UE. ¿Una fórmula institucional de evaluación?», año 2004, op. cit., págs. 72-73.

12 Navarro Nieto, F., Rodríguez-Piñero Royo, Miguel C., y Gómez Muñoz, J.M., (directores), Manual de Derecho Social de la Unión Europea, año 2011, op. cit., págs. 42-45. 
b) Funcionamiento del MAC

A través del $\mathrm{MAC}^{13}$, los Estados miembros acuerdan objetivos comunes, en calendarios y objetivos específicos, que deben traducirse en acciones nacionales y regionales. La Comisión supervisa el desarrollo de estas acciones con indicadores cuantitativos y cualitativos, parámetros y una evaluación comparativa; los Estados miembros presentarán informes periódicos a la Comisión.

El MAC comporta un sistema de seguimiento por el benchmarking, este sistema de evaluación del progreso es un elemento esencial del policy learning tool (herramienta de aprendizaje) con el peer review como mecanismo que asegura la aplicación de los procesos de coordinación de las políticas estructurales nacionales.

Para Pérez Menayo, el MAC ha demostrado ser un instrumento útil de avance, a través de la instauración de un sistema de evaluación institucional, en aquellos sectores de la política comunitaria donde no existen instrumentos de coordinación más fuertes. El MAC se transforma en un instrumento de gestión eficaz para hacer que la UE progrese de manera coordinada y más rápida en aquellos ámbitos hasta ahora reservados a la competencia nacional. En este ámbito, la Comisión juega un papel fundamental de coordinación, y de evaluación del conjunto de procesos.

Asimismo, para este autor el éxito del MAC reside en su flexibilidad y en su capacidad de contribuir a la convergencia progresiva de las políticas nacionales, en materias donde las reticencias de los Estados miembros no permiten la integración. El MAC se ha convertido en un instrumento útil de buen gobierno que debe completar el método comunitario. Además contribuye a generar consenso en la UE sobre la necesidad de proceder a reformas estructurales importantes y determinar objetivos estratégicos comunes en ámbito de políticas que son clave para alcanzar los objetivos de la Estrategia de Lisboa. Es también un mecanismo ventajoso para intercambiar las buenas prácticas y mejorar la coordinación de los Estados miembros. Sin embargo, este autor también reconoce las limitaciones del MAC para llevar a cabo los cambios estructurales necesarios en el entorno nacional. Considera necesario romper las inercias de aquellos Estados miembros reacios todavía a comprometerse con los objetivos acordados en común.

${ }^{13}$ Pérez Menayo, V., «El método abierto de coordinación en la UE. ¿Una fórmula institucional de evaluación?», año 2004, op. cit., págs. 86-96. 
Por otro lado, el método abierto de coordinación es considerado por algunos autores ${ }^{14}$ un nuevo instrumento de construcción de la Europa social. En el Tratado de Roma se introdujo la idea y el objetivo ambicioso de la armonización hacia el progreso a través de Directivas sociales, pero en realidad esa armonización, salvo en las Directivas de reestructuración de empresas, ha avanzado poco y no ha sido efectiva. Además, no han tenido éxito las propuestas de reforzamiento de las competencias sociales y de limitación de la regla de unanimidad en el proceso de adopción de las Directivas en materia social.

Las políticas de protección social ${ }^{15}$ iniciaron un proceso de cooperación, siguiendo el modelo de la Estrategia Europea de Empleo $^{16}$, con miras a su modernización respetando las diferencias nacionales. La Unión Europea tenía el reto de consolidar la protección social como un nuevo pilar social, desde una visión integrada, en la que la seguridad social quedará reforzada como un instrumento para el crecimiento económico y la cohesión social.

En septiembre de 1999, la Comisión Europea presentó la Comunicación: «Una estrategia concertada para modernizar la protección social». Dicha estrategia fue presentada en el Consejo de Ministros de Trabajo y Asuntos Sociales en octubre de 1999. Esto implicó una nueva apertura del debate sobre el futuro de los sistemas de protección social en la Unión Europea.

La Cumbre de Lisboa ordenó proseguir los trabajos en materia de protección social, en colaboración con el Comité de Política Económica y encomienda aplicar el método abierto de coordinación a la exclusión social a título experimental y con carácter previo a las pensiones. Posteriormente, la Cumbre de Gotemburgo (junio de 2001) con el pretexto de afrontar el reto de envejecimiento de la población estableció en su conclusión n. ${ }^{\circ} 43$, la aplicación del método abierto de coordinación a las pensiones, esto fue confirmado en el Consejo Europeo de Barcelona (marzo de 2002), bajo la presidencia española.

${ }^{14}$ Rodríguez-Piñero y Bravo Ferrer, M., «Constitución Europea, política social y método abierto de coordinación», Relaciones laborales: Revista crítica de teoría y práctica, n. ${ }^{\circ} 2,2005$, págs. 61-64.

${ }_{15}$ Pérez Menayo, V., «La Estrategia Europea de Protección Social: el Método Abierto de Coordinación». Comunicación Foro de Seguridad Social n. ${ }^{\circ} 8$ y 9. Editorial Análisis/Debate, abril 2003, págs. 80-87.

16 Estrategia Europea de Empleo. http://ec.europa.eu/social/main.jsp? catId=101\&langId=es. 
c) Dualidad institucional

El método abierto de coordinación ${ }^{17}$ significó un nuevo modelo de gobernanza con el que se ha pretendido resolver el bloqueo político e institucional en el que se encontraban las instituciones europeas. Debido a la creciente tendencia a la europeización económica, se requería una coordinación a nivel social ${ }^{18}$. Sin embargo, los Estados habían mostrado reticencias a delegar a nivel europeo las políticas sociales, tan marcadas por la cultura nacional e identidad política de cada país. A resultas de ello, las instituciones europeas se enfrentaban ante un dilema difícil de gestionar y por ello fue configurado el Método Abierto de Coordinación (MAC) dirigido fundamentalmente a regular el desempleo a nivel europeo.

Si miramos con una cierta perspectiva, se podría decir que el MAC generó un dualismo institucional en la Unión Europea ${ }^{19}$. Hasta ese momento, el método comunitario de gobierno había permitido fortalecer las instancias supranacionales, altamente centralizadas. Frente a esta tendencia, el Método Abierto de Coordinación propone un proceso político en ausencia de control democrático y jurídico que se hace efectivo a través de un enfoque gubernamental descentralizado, que integra directamente las opiniones de los diferentes niveles de poder y de la sociedad civil.

El MAC es considerado por Bárcena un gobierno débil de política económica comunitaria que llega avalado por su capacidad para combinar la coherencia con el respeto a diversidad institucional, y la eficiencia con la legitimidad democrática.

Este método no se ajusta a los parámetros generales del modelo institucional de la Unión, ni se canaliza a través de los procedimientos establecidos en las disposiciones establecidas de los Tratados, ni tampoco se traduce en normas de derecho comunitario.

El MAC se basa en decisiones flexibles, donde se pasa de un sistema basado en reglas y procedimientos sujetos a la observancia de la Comisión y el Tribunal de Justicia de la Unión Europea, a un sis-

17 Moreno, L., y Serrano, Pascual A., «Europeización del Bienestar y activación», año 2007, op. cit., págs. 37-42.

${ }^{18} \mathrm{El}$ «dumping social» era una práctica competitiva desleal basada en la explotación de los trabajadores para conseguir unos bajos costes laborales y ofrecer unos precios atractivos para los productos ofrecidos.

19 Bárcena, J.M., "La dimensión institucional y democrática de la gobernanza económica europea: el Método Abierto de Coordinación». Cuadernos Europeos de Deusto. Núm. 35/2006, Bilbao, págs. 23-42. 
tema basado en la decisión política consensuada y no vinculante de los Estados miembros.

La incertidumbre y la diversidad de las situaciones a las que se deben enfrentar los Estados miembros requieren de la utilización de un derecho descentralizado, elaborado a través de nuevas técnicas participativas, que se caracterice por su reversibilidad y su capacidad de adaptación a las nuevas situaciones planteadas por la realidad económica global.

Asimismo, el MAC ha generado un amplio debate entre partida$\operatorname{rios}^{20}$ y contrarios de aplicar este método a la materia social y laboral, lo que refleja un desacuerdo sobre la Europa social. El debate se desarrolla en torno al papel respectivo del hard law y del soft law; y versa sobre las ventajas de utilizar el método comunitario, de reglas uniformes vinculantes y sancionables judicialmente, frente a un método que establece orientaciones políticas, en vez de reglas, que no prevé sanciones formales y que no es justiciable.

Los contrarios a la utilización de este método consideran que se impide la elaboración del hard law, esencial para la construcción de la Europa social; para los partidarios, el MAC es una oportunidad para superar las dificultades del método comunitario y para facilitar lo que hoy se viene llamando «europeización» de la política social y el empleo, desde una nueva visión que destaca las dificultades actuales del método comunitario de reglas vinculantes en una Europa ampliada, al ser complicado encontrar soluciones iguales para sistemas nacionales muy distintos y para visiones muy distintas de la Europa social.

Se parte del prejuicio que el método abierto de coordinación no puede conseguir cambios reales ni crear derechos efectivos, lo que sí haría en todo caso el método comunitario a través de normas vinculantes. Aunque no cabe ignorar la importancia de la existencia de las normas, no siempre las Directivas comunitarias aportan los cambios legales uniformes que se proponían y se trasponen de forma adecuada, por ello se han tenido que hacer cada vez más abiertas. Sin embargo, el soft law puede ser un instrumento muy efectivo y puede hablarse de una cierta implementación en el ámbito nacional como actuación de Derecho comunitario.

No es menos cierto que con esta metodología no puede hablarse de sanciones jurídicas ni es posible que se pronuncie el Tribunal de Justicia, pero sí de otras sanciones como son el desprestigio, la ver-

${ }^{20}$ Rodríguez-Piñero y Bravo Ferrer, M., «Constitución Europea, política social y método abierto de coordinación», op. cit., 2005, págs. 66-69. 
güenza, la publicidad negativa y las presiones de las instituciones comunitaria en forma de recomendaciones críticas, de los otros Estados, y sobre todo, las internas a nivel nacional y local, pues el método genera procesos participativos a distintos niveles.

Finalmente, me referiré a la evaluación llevada a cabo por Jacques Toulemonde ${ }^{21}$ y varios de sus colegas para la Comisión Europea. La Evaluación de las Directrices Integradas para el Crecimiento y el Empleo ${ }^{22}$ tenía un fin formativo y fue ideada para proponer mejoras tanto en el contenido de las directrices como en el funcionamiento del proceso de coordinación.

La principal conclusión de este informe de evaluación según Toulemonde, fue que la aproximación de la «coordinación suave» es eficaz para fomentar el aprendizaje mutuo, incrementar el consenso entre las partes interesadas, reforzar la legitimidad de los promotores de la reforma, y finalmente para darle prioridad a las reformas en las agendas políticas. Sin embargo, este instrumento solo tiene un impacto marginal en la mayoría de los Estados Miembros, algo que se consideró un éxito dado que no se podía esperar mucho más de un mecanismo tan blando.

\section{I.3. El Pilar europeo de derechos sociales}

En septiembre de 2015, el Presidente de la Comisión Europea, Jean-Claude Juncker, con motivo de su primer discurso sobre el Estado de la Unión, declaró ${ }^{23}$ : «Tenemos que redoblar los esfuerzos encaminados a conseguir un mercado laboral justo y verdaderamente paneuropeo [...]. En el marco de estos esfuerzos, tengo la intención de desarrollar un Pilar europeo de Derechos Sociales que tenga en cuenta las cambiantes realidades de las sociedades europeas y el mundo del trabajo». Se trataba de un nuevo enfoque sobre el crecimiento basado en el empleo y la inclusión social ${ }^{24}$.

${ }^{21}$ Toulemonde, J., «Una evaluación del método abierto de coordinación de las políticas de los Estados miembros de la Unión Europea». Revista Gestión y Análisis de Políticas Públicas. Nueva Época, n. ${ }^{\circ}$ 4, julio-diciembre 2010, págs. 1-24.

${ }^{22}$ Vid. Evaluación de las Directrices Integradas para el Crecimiento y el Empleo. http://ec.europa.eu/economy_finance/evaluation/pdf/final_report_ipg_en.pdf. Y vid. también las Directrices Integradas para el Crecimiento y el Empleo. http://eur-lex. europa.eu/legal-content/ES/TXT/PDF/?uri=CELEX:32005D0600\&from=ES

${ }^{23}$ Discurso de Estado de la Unión, septiembre 2015. http://europa.eu/rapid/ press-release_SPEECH-15-5614_es.htm

${ }^{24}$ A lo largo de las siguientes páginas seguiremos algunas ideas de Ramos Quintana, M.I., «El Pilar Europeo de Derechos Sociales: La nueva dimensión social europea». Revista de Derecho Social, N. ${ }^{\circ}$ 7, año 2017, págs. 19-42. 
Este nuevo Pilar Europeo de Derechos Sociales nacería como consecuencia de las medidas económicas adoptadas para paliar la crisis económica durante los años 2010-2015. Los países del sur de Europa han sido los más afectados por las medidas de contención del gasto público y disminución del déficit público. Los planes de estabilización y reformas estructurales que han tenido que acometer estos países, con mayor intensidad que el resto, han originado elevadas tasas de desempleo, pobreza y exclusión social.

Por el momento, tal y como señala Ramos Quintana, se desconoce si el Pilar social representa un verdadero compromiso hacia la convergencia social renovada, o es solo make-up ${ }^{25}$. En este ámbito, los sindicalistas de toda Europa ${ }^{26}$ están participando en la lucha para defender y preservar los derechos sociales, así como el modelo social europeo. Los movimientos sindicales consideran que estos derechos no son inamovibles y que por tanto hay que estar alerta y preparados para defenderlos.

En la Cumbre Social de Gotemburgo celebrada el 17 de noviembre de 2017, se firmó una declaración conjunta sobre la implementación del «Pilar Social» por tres instituciones ${ }^{27}$ : la Comisión, el Consejo y el Parlamento Europeo. Esto ha supuesto un importante hito, demostrando la responsabilidad y el compromiso asumido por las tres instituciones. Se parte de que el Pilar Europeo de Derechos Sociales proclama una serie de principios y veinte retos. Se basa en tres principios esenciales: la igualdad de oportunidades y acceso al mercado de trabajo; condiciones de trabajo justas y unos sistemas de protección social adecuados y sostenibles.

Posteriormente, en el Consejo Europeo de 14 de diciembre de 2017, uno de los principales asuntos tratados fue la «Dimensión social, educación y cultura». Los dirigentes destacaron la importancia que reviste esta dimensión a la hora de acercar a los europeos entre sí y construir nuestro futuro común. Si bien en virtud de los Tratados la competencia en estos ámbitos sigue correspondiendo a los Estados miembros, se puede conseguir mucho mediante la colaboración, respetando los principios de subsidiariedad y proporcionalidad. En concreto, se pidió implantar el Pilar Europeo de los

${ }^{25}$ Ramos Quintana, M.I., «El Pilar Europeo de Derechos Sociales: La nueva dimensión social europea», año 2017, op. cit., pág. 42.

${ }^{26}$ Bischoff, G., «El modelo social europeo y los derechos de los trabajadores: ¿por qué necesitamos un pilar europeo de derechos sociales?». Temas para el Debate, n. 268 (marzo), año 2017, págs. 29-31.

27 Aplicación del Pilar Social. / http://www.europarl.europa.eu/RegData/etudes/ ATAG/2017/614622/EPRS_ATA(2017)614622_ES.pdf

(c) UNED. Revista de Derecho UNED, núm. 23, 2018 
Derechos sociales, teniendo siempre presente los ámbitos de competencia de los Estados miembros y de la Unión Europea, con una supervisión adecuada por parte de la Comisión.

Europa debe reinventarse ${ }^{28}$ siendo para ello necesario aumentar el nivel de protección de los derechos sociales fundamentales; las libertades económicas no pueden ignorar el impacto de los derechos sociales fundamentales.

Según Oliver De Schutter y Paul Dermine se hace necesaria una evaluación del impacto de los derechos sociales fundamentales en la nueva gobernanza socio-económica. La crisis ha puesto en evidencia el desequilibrio entre la constitución económica y social de la Unión Europea y la necesidad de reestructurar la Unión Económica Monetaria. Los derechos sociales fundamentales no han servido de guía ni de limitación a la hora de llevar a cabo medidas de austeridad o recortes en los países miembros. Los actores institucionales (Parlamento europeo, parlamentos nacionales...) deberían haber contribuido a preservar estos derechos, sin embargo fueron ampliamente marginados. Los memorándums de entendimiento acordados en los países rescatados, han violado muchos de los derechos establecidos en la Carta de los Derechos Fundamentales, sin que el TJUE los haya defendido, y posicionándose a favor de las medidas económicas y de austeridad amparándose en la primacía del Derecho de la Unión.

Por tanto, se hace necesario reformular el marco europeo político donde los derechos sociales fundamentales sean tenidos en cuenta. Existen presiones desde fuera de la Unión Europea para que esto sea así. El Comité Europeo de Derechos Sociales encargado de monitorear el cumplimiento de la Carta de Derechos Sociales, así como los órganos de Tratados de los Derechos Humanos han manifestado su interés de que se tenga más en consideración a los derechos sociales en las políticas de consolidación fiscal y en las reformas estructurales en base a los requerimientos del Semestre Europeo o en cumplimiento del Pacto Fiscal.

El Pilar Europeo de Derechos Sociales puede ayudar a equilibrar lo económico y lo social en la constitución de la Unión Europea. Lo puede hacer de tres formas: la primera construyendo un marco que evalúe los impactos de los Programas de Estabilidad presentado por los países miembros de la Unión y las recomendacio-

${ }^{28}$ De Schutter, O., and Dermine, P., «The two Constitutions of Europe: Integrating Social Rights in the New Economic Architecture of the Unión». Diciembre de 2016, Université Catholique Lovain, Institute for Interdisciplinary Research in Legal sciences. CRIDHO Working Paper 2016/2, págs. 1-40. 
nes hechas a los Estados miembros a través del Semestre europeo, así como los programas de ajustes. En segundo lugar, tal y como ha puesto de manifiesto la Comisión Europea, las futuras reformas deberían estar sujetas a una evaluación de impacto social, así como prestar una mayor atención a la equidad social en los nuevos programas de ajuste macroeconómicos. En tercer lugar, el nuevo Pilar social podría liderar nuevas normativas en el seno de la Unión Europea, como por ejemplo, los salarios mínimos, cuya regulación por cada país ha generado divergencias y riesgos de aumentar el dumping social.

Otra idea que establecen los autores antes referidos es otorgar competencias a la Agencia de Derechos Fundamentales para que guíe la actuación y las decisiones del Semestre Europeo, donde también es necesario la mayor participación de parlamentos, tanto europeo como nacionales, y la sociedad civil, y que sus voces sean consideradas en el seno del Semestre europeo.

Finalmente podemos destacar, como se ha dicho antes, la necesidad de que el Pilar Europeo de Derechos Sociales tenga más en consideración a los derechos sociales establecidos en la Carta Social Europea. Y para ello, tal y como señalan las recomendaciones de la Resolución del Parlamento Europeo sobre la propuesta del Pilar Europeo de Derechos Sociales del 19 de enero de 2017, se hace necesario promover la firma y ratificación de la Carta Social Europea revisada y se alienta a la Comisión para que estudie las medidas necesarias para la adhesión de la Unión Europea a la Carta Social revisada.

\section{LA CARTA SOCIAL EUROPEA. DEBATE SOBRE SU ADHESIÓN}

La Carta Social Europea ${ }^{29}$, considerada la Declaración de derechos sociales más completa en el ámbito europeo, no forma parte de los Tratados de la Unión Europea pero fue incorporada expresamente al texto articulado del Tratado de Ámsterdam, de 2 de octubre de 1997 (anteriormente, sólo se había incluido en el Preámbulo del Acta Única Europea en 1986) sirviendo como orientación de los órganos comunitarios y en especial del Tribunal de Justicia de Luxemburgo.

29 De la Villa de la Serna, P., «Las tres Cartas europeas sobre derechos sociales». Revista del Ministerio de Trabajo y Asuntos Sociales, n. ${ }^{\circ}$ 32, 2001, pág. 273. 
La Carta Social Europea fue adoptada en Turín el 18 de octubre de $1961^{30}$ y entró en vigor el 26 de febrero de 1965. Se trata del Convenio más importante en cuanto a la protección de los derechos humanos sociales, conceptuándolo la doctrina ${ }^{31}$ como «el instrumento internacional que contiene el más amplio catálogo de derechos sociales». En el Proceso de Turín 2014 y los eventos posteriores que se han desarrollado se elevó la Carta social Europea a al estatus de Constitución Social Europea, la cual está suscrita por 43 de los 47 países que forman el Consejo de Europa, incluidos los 28 de la Unión Europea.

Los derechos sociales son considerados como secundarios en relación con los derechos civiles y políticos, y el mecanismo de control $^{32}$ que establece la Carta Social Europea para proteger los derechos, es bastante débil, al basarse exclusivamente en el examen de informes sometidos periódicamente a un Comité de expertos independientes por parte de los Estados; sistema que se encontraba en las antípodas del mecanismo propiamente jurisdiccional del CEDH. La Ex Secretaria General del Consejo de Europa, la Sra. Lalumière, con ocasión de un encuentro interregional organizado por el Consejo de Europa en enero de 1993, califico la Carta como la «hermana pobre» del Convenio Europeo de Derechos Humanos (CEDH).

En 1996, la Carta Social Europea fue revisada (en adelante se llamará CSER); por una parte, se actualizó la lista de los derechos garantizados, modernizando la problemática de algunos de ellos y, por otra parte, se añadieron derechos nuevos. Un año antes, en 1995, se había mejorado el mecanismo de control o garantía, mediante la adopción del Protocolo que establece un procedimiento de reclamaciones colectivas, que consiste en un procedimiento judicial que dota de mayor eficacia y efectividad a los derechos reconocidos en la Carta Social.

En todo caso, sería conveniente aproximar los dos instrumentos, de forma que la CSE alcance un nivel de protección comparable al del Convenio. El desarrollo del CEDH se asienta en buena parte en el dinamismo interpretativo del Tribunal Europeo de Derechos Hu-

30 Salcedo Beltrán, M.C., «La aplicabilidad directa de la Carta Social Europea por los órganos judiciales». Revista Trabajo y Derecho 13/2016 (enero), n. ${ }^{\circ}$ 13, 1 de enero de 2016; págs. 1-6.

${ }_{31}$ Belorgey, J.M., "La Carta Social Europea del Consejo de Europa y su órgano de control: el Comité Europeo de Derechos Sociales», Revista de Derecho Politico, n. ${ }^{\circ} 70,2007$, pág. 349.

${ }^{32}$ Akandji-Kombe, J.F., "Carta Social Europea y Convenio Europeo de Derechos Humanos: Perspectivas para la próxima Década». Revista de Derecho Politico, núm. 68, año 2006, págs. 387-407. 
manos. Éste ha propiciado una evolución de las normas extrayendo de ellas nuevas implicaciones o nuevas exigencias, haciendo del Convenio un instrumento vivo. Por tanto, si se pretende que la Carta sea un instrumento de protección efectiva de los derechos sociales, se impone que el Comité Europeo de los Derechos Sociales promueva ese mismo dinamismo interpretativo.

Como conclusión de lo anterior podemos decir, si el Derecho Europeo de los Derechos Humanos ${ }^{33}$ está integrado por la normativa de la Unión Europa y del Consejo de Europa, se hace necesaria una complementariedad y una interacción normativa de ambos ${ }^{34}$ foros. En el marco del principio de igualdad, el Comité Europeo de Derechos Sociales ha empezado a forjar un Derecho europeo antidiscriminatorio que ha favorecido la igualdad de oportunidades de grupos vulnerables. En este sentido, el Comité no sólo ha tenido en cuenta la labor desempeñada por otros órganos (sobre todo la jurisprudencia del Tribunal Europeo de Derechos Humanos) sino que incluso ha llegado a superarla, en una labor positiva de complementariedad. Una complementariedad que debería producirse cuando se compara el trabajo realizado por la Unión Europea y por el Consejo de Europa, sin embargo existen determinados obstáculos que impiden la complementariedad de ambos foros de manera fluida, como es la adhesión de la Unión Europea a la Carta Social Europea, ${ }^{35}$ como instrumento básico de derechos sociales e igualdad.

La adhesión de la Unión Europea al Convenio Europeo de Derechos Humanos debería ir acompañada paralelamente de la adhesión de la Unión a la Carta Social Europea del Consejo de Europa de modo que ${ }^{36}$ "la democracia política y social vayan de la mano, y por coherencia con el principio de indivisibilidad de los derechos huma-

33 Jimena Quesada, L., y Tomás Mallén B., "Hacia un estándar europeo común de igualdad: La contribución del Comité Europeo de Derechos Sociales». Revista de Derecho Político, núm. 68, 2007, págs. 353-357.

${ }^{34}$ Léase el trabajo de Flauss, J.F., "Las interacciones normativas entre los instrumentos europeos relativos a la protección de los derechos sociales», en el colectivo Escritos sobre Derecho europeo de los derechos sociales (coord. L. Jimena Quesada), Valencia, Tirant lo Blanch, 2004, pp. 25-54.

${ }^{35}$ Véase De Schutter, O., «L'adhésión de L’Unión européenne à la Charte sociale européenne révisée», EUI Working Papel LAW No. 2004/11. European University Institute, Florence, 2004. Acúdase asimismo a Jimena Quesada, L., "Sistema europeo de derechos fundamentales», en particular capítulo 7 (apartado IV.2: «la necesaria adhesión de la Unión Europea a la Carta Social Europea»). Marcial Pons, año 2006.

${ }^{36}$ Jimena Quesada, L., y Tomás Mallén B., «Hacia un estándar europeo común de igualdad: La contribución del Comité Europeo de Derechos Sociales», año 2007 op. cit., págs. 355 . 
nos.» Además, la importancia de su adhesión radica en evitar divergencias o contradicciones entre el Tribunal de Justicia de la Unión y el Comité Europeo de Derechos Sociales.

La existencia de diferentes mecanismos ${ }^{37}$ de garantía en el Convenio Europeo (CEDH) y en la Carta Social Europea, puede generar contenciosos paralelos entre dichos mecanismos (TEDH y CEDS) debido a la coincidencia en algunas materias (trabajo forzado, sindicación, educación, etc.). Estos contenciosos pueden generar divergencias jurisprudenciales, como así sucedió con la cláusula de democracia militante o beligerante de los funcionarios públicos de Alemania, que había sido avalada en un primer momento por la Corte Europea $^{38}$ mientras que el CEDS la había puesto en duda ${ }^{39}$.

Por otro lado, los contenciosos también han hecho emerger una voluntad positiva de enriquecimiento mutuo. Por ejemplo, el CEDS había elaborado una interpretación más flexible y dinámica de la libertad sindical (artículo 6 CSE) que la jurisprudencia inicial más restrictiva de dicha libertad establecida por la Corte Europea, la cual ha sido objeto de recepción por la jurisprudencia ulterior del TEDH, con mención expresa de la jurisprudencia del CEDS.

También han generado conflictos las sentencias y resoluciones de las tres instancias (TEDH, CEDS y TJUE) en el terreno de las fricciones entre las libertades económicas de circulación y algunos derechos sociales de acción colectiva. Las SSTJUE, Viking (del 11 de diciembre de 2007, asunto 438/05); Laval (del 18 de diciembre de 2007, asunto C-314/05), Rüffert (de 3 de abril de 2008, asunto C-346/06), Comisión c. Luxemburgo (de 19 de junio de 2008, asunto C-319/06) o Comisión c. Alemania (del 15 de julio de 2010, asunto C.271/08) presentan divergencias con respecto a la jurisprudencia del TEDH o la jurisprudencia del CEDS.

En este sentido el autor Baquero $\mathrm{Cruz}^{40}$ ha señalado «la UE necesita de los derechos sociales para reflejar de forma sustancial el prin-

37 Jimena Quesada, L., «La jurisprudencia europea sobre derechos sociales». Biblioteca Jurídica Virtual del Instituto de Investigaciones Jurídicas de la UNAM, https://archivos.juridicas.unam.mx/www/bjv/libros/7/3063/13.pdf de 1986.

${ }^{38}$ SSTEDH Glasenapp c. Alemania y Kosiek c. Alemania, ambas de 28 de agosto

${ }_{39}$ Recueil de la jurisprundence relative a la Charte sociale européenne, Strasboug, Conseil de l'Europe, Supplement 1, 1986, p.2; así como Recueil de la jurisprudence relative a la Charte sociale européenne, Supplement 3, 1993, p. 2.

${ }^{40}$ Baquero Cruz, J., «La protección de los derechos sociales de la Comunidad Europea tras el Tratado de Ámsterdam», Revista de Derecho Comunitario Europeo, núm. 4, año 1998, p. 666. 
cipio social de la Comunidad y contrarrestar la fuerza expansiva del principio liberal de mercado contenido en las normas de competencia y libre circulación de factores económicos».

El periodo de crisis económica ${ }^{41}$ ha conllevado la adquisición de un protagonismo sin precedentes de la Carta Social Europea, como el Tratado internacional de los derechos humanos de carácter social más importante. Esto ha llevado a que los órganos jurisdiccionales la hayan invocado directamente. Numerosas sentencias han sido publicadas desde el 19 noviembre de 2013, fecha clave en la que se sitúa la primera sentencia del orden de lo social ${ }^{42}$ que aplicó directamente la CSE y dejó sin efectos la normativa nacional que vulneraba o proporcionaba una protección inferior. En este caso concreto se dejaba en evidencia que el establecimiento del periodo de prueba del contrato de apoyo a los emprendedores vulneraba los derechos de la Carta Social Europea. Esta línea interpretativa ha continuado en otras materias como la desvinculación del incremento de las pensiones al IPC o el tiempo de trabajo.

En febrero de 2015 se elaboró, como parte del llamado «Proceso de Turín» (lanzado en octubre de 2014 por el Secretario General del Consejo de Europa), el Documento de Bruselas Sur l'avenir de la protection des droits sociaux en Europe ${ }^{43}$, elaborado por un grupo de expertos independientes, que cuenta con el respaldo del Consejo de Europa, en el que se fijan objetivos relativos a mejorar la protección de los derechos sociales, en concreto, su garantía en tiempos de crisis económica, la coherencia y coordinación entre los Estados y las organizaciones internacionales en cuanto a su protección, la mejora y avance de la eficacia de la Carta Social Europea, y la potenciación de las sinergias entre el Consejo de Europa y la UE.

En relación con esto, se ha producido una importante doctrina, que gira en torno al principio general del necesario respeto y garantía de los derechos sociales en todo momento y sobre todo en tiempos de crisis. A modo de ejemplo, la SJS de Barcelona n. ${ }^{\circ} 2$ de 19 de noviembre de 2013 (n. ${ }^{\circ}$ 421/2013) donde se determina que «la crisis

${ }^{41}$ Salcedo Beltrán, MC., «La aplicabilidad directa de la Carta Social Europea por los órganos judiciales», año 2016, op. cit., págs. 1-28.

${ }^{42}$ Sentencia n. ${ }^{\circ} 412 / 2013$ del Juzgado de lo Social n. ${ }^{\circ} 2$ de Barcelona, de 19 de noviembre de 2013. http://www.cgsm.es/novedades-legislativas/sentencia_periodo_ de_prueba_emprendedores.pdf.

${ }_{43}$ Documento de Bruselas sur l'avenir de la protection des droits sociaux en Europe http://www.coe.int/t/dghl/monitoring/socialcharter/Doc_Bruxelles_version_EN_ FR_DEF.pdf 
económica no debe traducirse en una reducción de la protección de los derechos reconocidos por la Carta...; los Gobiernos deben adoptar todas las medidas necesarias para conseguir que esos derechos sean efectivamente garantizados en el momento en que la necesidad de protección se hace sentir más».

Numerosos autores ${ }^{44}$ suscriben la obligatoriedad, que son «la concreción de las obligaciones jurídicas asumidas al comprometerse con la Carta», que con su emisión el CEDS, quiere que el Derecho tome cuerpo, es decir no se conforma con los buenos usos, sino que considera necesario una base jurídica habilitante para los derechos reconocidos y que estos puedan ser movilizados.

Por el contrario, si hay cierta divergencia en cuanto a considerarlo «jurisprudencia». El Parlamento Europeo en su informe de 16 de julio de 2015 sobre la situación de los derechos fundamentales en la Unión Europea (2013-2014) o la Resolución de 27 de febrero de 2014 sobre la situación de los derechos fundamentales en la Unión Europea, señaló expresamente "vistas la Carta Social Europea, revisada en 1996, y la jurisprudencia del Comité Europeo de Derechos sociales». En todo caso, existe otro sector de la doctrina que niega el carácter vinculante del CEDS $^{45}$, llegando a expresar que éste no impone «ningún comportamiento a los Estados concernidos sino que se limita a declarar la conformidad o disconformidad con la CSE de la legislación nacional».

Como conclusión, podemos apuntar que la crisis económica ha llevado a que los jueces y magistrados tengan que conocer la CSE y la jurisprudencia del CEDS, ya que en estos momentos es el Tratado más importante en cuanto a la protección de derechos sociales, que al equipararlos al resto de derechos, establece un nivel de protección más elevado que el de las normas estatales o de otras organizaciones del mismo carácter, en las que se prioriza las libertades económicas o se justifica la crisis como criterio de restricción de los derechos. Por ello, es necesario que los profesionales invoquen la CSE como un instrumento de garantía de derechos y que se observen los man-

44 Jimena Quesada L., «La ejecución de las decisiones del Comité Europeo de Derechos Sociales» en AA.VV., Tratado sobre protección de derechos sociales. Tirant lo Blanch, Valencia 2014, pág. 252.; Akandji-Kombé, J.F., «Les obligations positives et la protection des droits sociaux dans le systéme europeen des droit de l'homme». Contribution a la Conference de Haut Neveau sur la Charte Sociale Europeenne (Turin, 17 et 18 octobre 2014).

${ }^{45}$ Canosa Usera, R., «La protección de los derechos sociales en el ámbito del Consejo de Europa», Ponencia impartida en las Jornadas de Derecho Laboral sobre; Reforma laboral: Sentencias del Tribunal Constitucional, Derechos Fundamentales y Derecho Internacional. Madrid 8 y 9 de julio de 2015, pág. 19. 
datos constitucionales en cuanto al efecto directo de una norma internacional.

Asimismo, cabe señalar que el documento de las prioridades adoptadas por el Consejo de la UE de enero de $2016^{46}$, señaló la importancia de «reforzar la cooperación y el diálogo periódico con el Consejo de Europa sobre la interacción entre la Carta Social Europea y las leyes y políticas de la Unión Europea, teniendo en cuenta las respectivas estructuras jurídicas y políticas y las competencias de la UE y el Consejo de Europa».

Del mismo modo, el documento "Avis du Secrétaire Général du Conseil de l'Europe sur l'initiative visant la mise en place d'un socle européen des droits sociaux par l'Unión européenne» de 2 de diciembre de 2016, recomendó "que las disposiciones de la Carta Social Europea revisada, deberían incorporarse formalmente al Pilar Europeo de Derechos Sociales como un punto de referencia común para los Estados en garantía de esos derechos» ${ }^{47}$.

Por tanto, los desafíos futuros en cuanto a los derechos sociales tanto en el ámbito normativo como en el ámbito jurisprudencial $^{48}$ deben plasmarse en el marco del «Pilar Europeo de los derechos sociales». Este Pilar, promovido desde la Unión Europea, debe ponerse necesariamente en conexión con el citado «Proceso de Turín» que tuvo su origen en una Conferencia en Turín en octubre de 2014 promovida por el Consejo de Europa y que tenía como objetivo estrechar las relaciones entre el sistema normativo de la Carta Social Europea del Consejo de Europa y la normativa de la Unión Europea.

46 Documento del Consejo de la Unión Europea «Prioridades de la UE en materia de cooperación con el Consejo de Europa en 2016-2017»/ http://data.consilium. europa.eu/doc/document/ST-5339-2016-INIT/es/pdf

${ }^{47}$ Documento "Avis du Secrétaire Général du Conseil de l'Europe sur l'initiative visant la mise en place d'un socle européen des droits sociaux par l'Unión européenne». https://rm.coe.int/CoERMPublicCommonSearchServices/DisplayDCTMCon tent?documentId=09000016806dd0bd

48 Jimena Quesada, L., "The asymmetric evolution of the social case-law of the Court of Justice: new challenges in the context of the European pillar of social rights». University of Minho, UNIO-EU Law Journal. Vol. 3, No. 2, July 2017, pages 4-19. 


\section{EL TJUE COMO GARANTE DE LOS DERECHOS FUNDAMENTALES}

En el ámbito judicial, el TJUE ha antepuesto por norma general la supervivencia de la libre competencia y la economía de mercado ${ }^{49}$, a los derechos sociales fundamentales. Se fundamenta en la primacía del Derecho de la Unión, insistiendo en la garantía de los derechos como principios generales de la Unión; la Carta Europea de Derechos Fundamentales tiene la finalidad de proteger la aplicación uniforme del Derecho europeo y no a sus ciudadanos, como se ha visto fundamentalmente en época de crisis económica.

Las citadas sentencias Viking (de 11 de diciembre de 2007, asunto C-438/05), Laval (de 18 de diciembre de 2007, asunto C-341/05). y Rüffert (de 3 de abril de 2008, asunto C-346/06), han permitido al TJUE resolver conflictos entre libertades fundamentales y derechos sociales mediante un test de proporcionalidad donde han pesado más los argumentos basados en la libertad de mercado «altamente competitiva» que aquellos basados en el fomento de la justicia, la protección social o la cohesión social.

La sentencia Pringle ${ }^{50}$ del año 2012, pone de manifiesto como la Carta de Derechos Fundamentales no es parámetro de control del MEDE ni de los Memorandums de entendimiento. El TJUE desde una postura muy integracionista y en defensa del proyecto común europeo ha justificado el encaje del MEDE en el Derecho europeo.

Sin embargo, el caso Ledra Advetising ${ }^{51}$ en el 2016, ha supuesto un punto de inflexión en cuanto a la defensa de los derechos fundamentales por parte del TJUE. Este caso muestra cómo la Comisión Europea está ligada con el cumplimiento de la Carta de los Derechos Fundamentales, y como debe velar por que se cumpla en la negociación e implementación de los Memorandums.

49 Aguilar Calahorro, A., «La posición del Tribunal de Justicia de la Unión Europea en relación a las medidas adoptadas ante la crisis económica» en Balaguer Callejón F., Azpitarte Sánchez M, Guillen López E., Sánchez Barrilao, J.F., El Impacto de la crisis económica en las instituciones de la UE y los Estados miembros, año 2015, Pamplona. Thomson Reuters Aranzadi, págs. 144-146; 129-159.

${ }_{50}$ Aguilar Calahorro, A., «La Decisión Pringle en el proceso de constitucionalización de la Unión Europea», en Revista Española de Derecho Constitucional, 2014, págs. 344-366.

${ }^{51}$ De Montalvo Jääskeláinen, F., «El Tribunal de Justicia al rescate de los derechos en el contexto de las medidas de estabilidad derivadas de la crisis económica: Pringle V Ledra Advertising», en Teoría y Realidad Constitucional de la UNED, núm. 39, año 2017; págs. 629-635. 
El TJUE en este caso considera que el hecho de que las tareas confiadas a la Comisión y al BCE en el marco del Tratado del MEDE no comprendan ninguna potestad decisoria propia y sólo vinculen al MEDE, no excluye la posibilidad solicitar a la Comisión y al BCE una indemnización por daños y perjuicios fundada en el comportamiento ilícito que se les imputa en el marco de la adopción de un MoU en nombre del MEDE. Las tareas confiadas a la Comisión y al BCE en el marco del Tratado MEDE no desvirtúan las atribuciones que los Tratados UE y FUE confieren a estas instituciones; así en el ámbito del MEDE, la Comisión conserva «su misión guardiana de los Tratados», por lo que debería abstenerse de firmar un Memorandum que contenga dudas sobre los derechos fundamentales.

Cabe señalar que, si bien los Estados miembros no aplican el Derecho de la Unión en el marco del Tratado MEDE, de modo que la Carta no está incluida en dicho ámbito, la Carta sí está dirigida a las instituciones de la Unión también cuando actúen fuera del marco jurídico de ésta. Así la Comisión está obligada a velar por que el Memorandum sea compatible con los derechos fundamentales. De este modo, los ciudadanos europeos cuentan con un pequeño resquicio para que los Memorandums no violen estos derechos fundamentales. Parece que el TJUE está por la labor de volver a la senda de los derechos, lo que se podrá confirmar más adelante con nuevas sentencias.

\section{CONCLUSIONES}

1. Los protagonistas de la articulación del sistema de protección social continúan siendo los Estados miembros. La pretendida armonización de las políticas sociales que establecía el Tratado de Roma no ha sido satisfactoria, siendo necesario nuevos instrumentos más flexibles de coordinación, como son las normas de «soft law».

2. La Unión Europea pasa de estar gobernada exclusivamente por el modelo comunitario tradicional (directivas, reglamentos, etc.) a estarlo también por nuevos métodos (soft law o norma suave, como por ejemplo el MAC).

3. El éxito del MAC reside en su flexibilidad y en su capacidad de contribuir a la convergencia de las políticas nacionales en materias donde las reticencias de los Estados miembros no permiten su integración. 
4. La vuelta al intergubernalismo, que podría ser percibida como un retroceso en relación a los instrumentos de integración europea se ha convertido en el único medio de desbloqueo de la soberanía nacional.

5. El MAC se presenta como una oportunidad para superar las dificultades del método comunitario y para facilitar la europeización de la política social y de empleo. Se considera un instrumento efectivo y puede hablarse de una cierta implementación en el ámbito nacional como actuación del Derecho comunitario.

6. Para algunos autores, el MAC es considerado un «gobierno débil» de la política comunitaria. El MAC se basa en un sistema flexible basado en la decisión política consensuada y no vinculante de los Estados miembros.

7. El término «modelo social europeo» se sigue utilizando para describir los principios, valores y elementos comunes a los regímenes sociales vigentes en la Unión. El Modelo social europeo se fundamenta en la solidaridad y promueve la ciudadanía social, entendida como una limitación a la desigualdad social y económica, una mayor protección a los más vulnerables y un paternariado social activo.

8. Sin embargo, la Unión Europea no ha configurado un modelo social propio, ni un modelo compartido por los Estados miembros. Se confiaba en que las políticas económicas de un mercado común produjeran el progreso social.

9. El modelo social europeo debe renovarse, promoviendo los instrumentos de coordinación (a través de las normas de soft law o el MAC), estableciendo si fuera necesario un nuevo reparto de competencias entre la Unión y los Estados e impulsando el acercamiento y la compatibilidad de los diversos sistemas nacionales.

10. El Pilar Europeo de Derechos Sociales promovido por la Comisión Europea puede ser una oportunidad para resetear el modelo social de la Unión teniendo en cuenta las cambiantes realidades de las sociedades europeas y del mundo del trabajo. Es fundamental que se garanticen los derechos fundamentales y los derechos sociales en tiempos de crisis económica donde se aplican reformas y medidas de austeridad.

11. Este Pilar puede liderar campos de actuación que hasta ahora habían sido dirigidos por los Estados miembros, como por ejemplo: salarios más justos, con el fin de evitar riesgos como el dumping social. 
12. Otra idea interesante es que la Agencia Europea de Derechos fundamentales, no sólo sea un órgano de información y consulta sino que se convierta en un órgano de vigilancia y control de estos derechos, sobre todo en decisiones económicas tan importantes como el Semestre Europeo o el MEDE.

13. La adhesión de la UE a la Carta Social Europea podría ser impulsada por el Pilar Europeo de Derechos sociales. El periodo de crisis económica ha llevado a que la Carta Social Europea adquiera un protagonismo sin precedentes en Europa y a que los órganos jurisdiccionales la invoquen directamente. Se hace necesario que los órganos jurisdiccionales invoquen la CSE como un instrumento de garantía de derechos y que se observen los mandatos constitucionales en cuanto al efecto directo de una norma internacional.

14. La jurisprudencia del TJUE ha entrado en conflicto cuando están en juego los derechos sociales frente a las libertades económicas, donde han prevalecido por norma general las segundas. Esta posición debe ir moviéndose hacia una ponderación más equilibrada entre las libertades económicas y los derechos fundamentales.

\section{BIBLIOGRAFÍA UTILIZADA}

Aguilar Calahorro, A., «La posición del Tribunal de Justicia de la Unión Europea en relación a las medidas adoptadas ante la crisis económica» en Balaguer Callejón F., Azpitarte Sánchez M, Guillen López E., Sánchez Barrilao, J.F., El Impacto de la crisis económica en las instituciones de la UE y los Estados miembros, año 2015, Pamplona. Thomson Reuters Aranzadi, págs. 144-146; 129-159.

Aguilar Calahorro, A., «La Decisión Pringle en el proceso de constitucionalización de la Unión Europea», en Revista Española de Derecho Constitucional, 2014, págs. 344-366.

AKandJ-Kombe, JF., "Carta Social Europea y Convenio Europeo de Derechos Humanos: Perspectivas para la próxima Década». Revista de Derecho Político, núm. 68, año 2006, págs. 387-407.

AKANDJI-KomBÉ, J.F., "Les obligations positives et la protection des droits sociaux dans le systéme europeen des droit de l'homme». Contribution a la Conference de Haut Neveau sur la Charte Sociale Europeenne (Turin, 17 et 18 octobre 2014).

Baquero Cruz, J., "La protección de los derechos sociales de la Comunidad Europea tras el Tratado de Ámsterdam», Revista de Derecho Comunitario Europeo, núm. 4, año 1998, p. 666. 
BÁRCENA, JM., «La dimensión institucional y democrática de la gobernanza económica europea: el Método Abierto de Coordinación». Cuadernos Europeos de Deusto. ISSN: 1130-8354, núm. 35/2006, Bilbao, págs.23-42.

BARÓN CRESPo, E., "Constitución y modelo social europeo», en Estudios de economía aplicada, vol. 27-3, 2009, págs. 599-608.

Belorgey, J.M., «La Carta Social Europea del Consejo de Europa y su órgano de control: el Comité Europeo de Derechos Sociales», Revista de Derecho Político, n. ${ }^{\circ} 70,2007$, pág. 349.

Bischoff, G., «El modelo social europeo y los derechos de los trabajadores: ¿por qué necesitamos un pilar europeo de derechos sociales». Temas para el Debate, ISSN 1134-6574, n. ${ }^{\circ} 268$ (marzo), año 2017, págs. 29-31.

CAFARo, S., "La méthode ouverte de coordinaction, l'action communautaire et le rôle politique du Conseil européen» en Mélangesen hommage a Jean-Victor Louis, Ed. ULB, 2003, Vol. II, pp. 204 y ss.

Canosa Usera, R., "La protección de los derechos sociales en el ámbito del Consejo de Europa». Ponencia impartida en las Jornadas de Derecho Laboral sobre; Reforma laboral: Sentencias del Tribunal Constitucional, Derechos Fundamentales y Derecho Internacional. Madrid 8 y 9 de julio de 2015, pág. 19.

De la Villa de la Serna, P., «Las tres Cartas europeas sobre derechos sociales». Revista del Ministerio de Trabajo y Asuntos Sociales, ISSN 1137-5868, n. . 32, 2001, página 273.

De Schutter, O., and Dermine, P., «The two Constitutions of Europe: Integrating Social Rights in the New Economic Architecture of the Unión». Diciembre 2016, Université Catholique Lovain, Institute for Interdisciplinary Research in Legal sciences. CRIDHO Working Paper 2016/2, pags. 1-40.

De Schutter, O.: «L'adhésión de L’Unión européenne à la Charte sociale européenne révisée», EUI Working Papel LAW No. 2004/11. European University Institute, Florence, 2004.

FLAUSS, J.F., «Las interacciones normativas entre los instrumentos europeos relativos a la protección de los derechos sociales», en el colectivo Escritos sobre Derecho europeo de los derechos sociales (coord. L. Jimena Quesada), Valencia, Tirant lo Blanch, 2004, pp. 25-54. 
González Vázouez, I., El Cambio de Orientación de la Política Social Comunitaria del Estado del Bienestar a la Sociedad del Bienestar, Universidad de Sevilla, 2011.

GuAmán, A. y Noguera, A., Derechos sociales, integración económica y medidas de austeridad: la UE contra el constitucionalismo social, editorial Bormazo; año 2014.

Imani, E., "Méthode ouverte de coordination». E-juristes. Febrero de 2005. http://www.e-juristes.org/methode-ouverte-decoordination647/ (Consulta 30 de abril 2005).

JiMENA QUESADA, L., «La jurisprudencia europea sobre derechos sociales». Biblioteca Jurídica Virtual del Instituto de Investigaciones Jurídicas de la UNAM, págs. 297-298; y págs. 300-308.

Jimena Quesada L., y Tomás Mallén, B., «Hacia un estándar europeo común de igualdad: La contribución del Comité Europeo de Derechos Sociales». UNED. Revista de Derecho Político, núm. 68, 2007, págs. 353-357.

Jimena Quesada L., «La ejecución de las decisiones del Comité Europeo de Derechos Sociales» en AA.VV., Tratado sobre protección de derechos sociales. Tirant lo Blanch, Valencia 2014, pág. 252.

JiMENA QUESADA, L., "The asymmetric evolution of the social case-law of the Court of Justice: new challenges in the context of the European pillar of social rights». University of Minho, UNIO-EU Law Journal. Vol. 3, No. 2, July 2017, pages 4-19.

Martínez Rocamora, L., «La Política social de la Comunidad económica Europea», Cuadernos de la Facultad de Derecho, 1991, Vol 17, páginas 65-70.

Moreno, L. y SERrano, A., "Europeización del Bienestar y activación». Revista Política y Sociedad, 2007, Vol. 44; núm. 2; págs. 31-44.

MoReno, L., «Reformas y Reestructuración del Estado del Bienestar en la Unión Europea». Instituto de Políticas y Bienes Públicos (IPP) CSIC, Working Paper 2004-09, págs.3-4.

Navarro Nieto, F., Rodríguez Piñero Royo, Miguel, C. y Gómez, J.M., Manual de Derecho Social de la Unión Europea, Año 2011.

Pérez Menayo, V., «El método abierto de coordinación en la UE. ¿Una fórmula institucional de evaluación?» en Gestión y Análisis de Políticas Públicas, mayo-diciembre 2004. Págs. 72-74; 86-96.

(C) UNED. Revista de Derecho UNED, núm. 23, 2018 
Pérez Menayo, V., «La Estrategia Europea de Protección Social: el Método Abierto de Coordinación». Comunicación Foro de Seguridad Social n. ${ }^{\circ} 8$ y 9. Editorial Análisis/Debate, abril 2003, págs. 80-96.

Ramos Quintana, MI., «El Pilar Europeo de Derechos Sociales: La nueva dimensión social europea». Revista de Derecho Social, ISSN 1138-8692 , n. ${ }^{\circ}$ 77, año 2017, págs. 19-42.

Rodríguez-PiÑERo y Bravo FerRer, M., «Constitución Europea, política social y método abierto de coordinación». Revista Relaciones Laborales, año 2005; págs. 61-69.

SAlCEdo Beltrán, MC., «La aplicabilidad directa de la Carta Social Europea por los órganos judiciales». Revista Trabajo y Derecho 13/2016 (enero), n. ${ }^{\circ} 13,1$ de enero de 2016; págs. 1-28.

Toulemonde, J., «Una evaluación del método abierto de coordinación de las políticas de los Estados miembros de la Unión Europea». Revista Gestión y Análisis de Políticas Públicas. Nueva Época, n. ${ }^{\circ} 4$, julio-diciembre de 2010, págs. 1-24. 